\title{
Foreign language examples in chemical nomenclature Roger Sayle
}

\author{
Address: OpenEye Scientific Software, Suite \#D, 9 Bisbee Court, Santa Fe, New Mexico, NM 87508, USA \\ from 3rd German Conference on Chemoinformatics \\ Goslar, Germany. II-I3 November 2007 \\ Published: 26 March 2008 \\ Chemistry Central Journal 2008, 2(Suppl I):P29 doi:I0.II86/1752-I53X-2-SI-P29
}

This abstract is available from: http://www.journal.chemistrycentral.com/content/2/SI/P29

(C) 2008 Sayle

This poster is a supplementary adjunct to the oral presentation "Breaking the Language Barrier: Chemical Nomenclature around the Globe". The poster will present numerous examples of the way that IUPAC and traditional nomenclature of chemical compounds is expressed/represented in various languages, such as British, American, German, Spanish, Swedish, Japanese, Polish, Russian, French, Dutch, Welsh, Navajo, Klingon etc... The divergence of chemical naming is associated with three chronological eras: (1) the pre-historic era, almost all languages have their own words for "water", "iron" and "gold"; (2) the traditional era following the systematization of chemistry by Antoine Lavoisier around the 1780s, including names like "acetic acid", "butyric acid" and the periodic table; and finally (3) the modern era following the on-going standardization efforts by IUPAC and the Chemical Abstracts Service. Comparing the native language differences in the names used in organic chemistry in the context of these three eras and nationality/geography, provides some interesting insights. 